\title{
The Impact of Stakeholder Involvement in Evaluation System Design: Lessons from the Zimbabwe Education Sector Experiences
}

\author{
Belinda R. Musodza \\ Elphinah N. Cishe \\ Neziwe Mapangwana \\ Department of Continuing \\ Professional Teacher Development, \\ Faculty of Educational Sciences, \\ Walter Sisulu University, \\ Nelson Mandela Drive, \\ Mthatha, 5100, South Africa
}

DOI: https://doi.org/10.36941/jesr-2021-0057

\begin{abstract}
The design of a performance evaluation system should ideally be inclusive and participatory to enhance stakeholders' buy-in, acceptance and ownership of the system, whilst at the same time, ensure relevance and sustainability of the process. This paper examines the design process of the teacher evaluation system in one education district of Zimbabwe. The study intended to establish the extent of teacher involvement in the design of the evaluation system and to determine the relationship between the design process and effectiveness of the evaluation system. The study used the convergent mixed method design. A quantitative sample of 292 teachers and a qualitative sample of 12 educators, namely teachers, heads of departments and school heads drawn from 10 secondary schools participated in the study. Quantitative data were analysed using SPSS version 26 and descriptive and inferential statistics were conducted. Atlas ti. 8 was used to analyse the qualitative data. The study established that the design process was exclusive and non-participatory, which led to lack of ownership and buy-in by the teachers. Based on these findings, it was concluded that the design process was faulty and negatively impacted the effectiveness of the teacher performance evaluation system. The study recommends that policy formulation should be inclusive and pilot tested to allow input of the users before full scale implementation.
\end{abstract}

Keywords: Buy-in, effectiveness, evaluation system, participatory, stakeholder involvement

\section{Introduction}

There has been increased calls for a results based culture, accountability, transparency and enhanced effectiveness for both the public and private sectors in the recent past (Kusek \& Rist, 2004). In response to the calls and increased pressure for improved quality and effective service delivery, many countries have set up evaluation systems to monitor and assess the performance of their workers. The education sector has not been spared in this struggle for better and more responsive services where the duty 
bearers are held to account. Teacher quality has been identified as any school's key driver towards effective learner education (Shinkfield \& Stufflebeam, 1995; Stronge \& Tucker, 2003; The New Teacher Project (TNTP), 2010) and evidence suggest that one way of ensuring effective learner education is by instituting well designed and properly implemented evaluation systems in the schools (Shinkfield \& Stufflebeam, 1995; Stronge, 2011; Stronge \& Tucker, 2003). The performance evaluation of teachers is therefore, believed to be instrumental in augmenting the provision of quality teaching if properly founded and inaugurated.

Many countries conduct some form of performance evaluation for the teachers, but there is general consensus that most of the current evaluation processes are cumbersome, and yet, unhelpful in achieving their intended purpose (Danielson \& McGreal, 2000) or proving their practical usefulness (Callahan \& Sadeghi, 2015). This consequently brings to the fore the question of why evaluations are failing in their mandate to improve the teachers' instructional capacity as well as holding the teachers to account.

Many probable reasons have been given for ineffective evaluation systems. The New Teacher Project (TNTP) (2010) asserts that most teacher evaluation systems suffer from a slew of design flaws. The design process is an important phase in the development of a performance evaluation system as it contributes to the effectiveness of the evaluation process. This paper focuses on the impact of stakeholder involvement in the design process of an evaluation system. Literature asserts that the design process should be inclusive and participatory to promote buy-in and minimise resistance from the stakeholders (Goe, Holdheide \& Miller, 2014; Heneman, Milanowski, Kimball \& Odden, 20o6; Mayne, 2007; Santiago \& Benavides, 2009; White, Cowhy, Stevens \& Sporte, 2012). We allude to the observations that an evaluation system borne out of a collaborative effort by the main stakeholders is better placed to earn respect and acceptance as it is more likely to be perceived as relevant, useful and fair (Goe et al., 2014; Stronge \& Tucker, 1999). The respect and acceptance of the performance evaluation system by the users in turn enhances its chances of being effective. The argument is that stakeholder involvement is critical in the design process of an evaluation system. This is reiterated by Clifford, Hansen and Wraight (2012) in their assertion that evaluation systems are more likely to be accepted, successfully implemented, and sustained if all key stakeholders are included in the design process.

Before proceeding further, there is need to clarify what is meant by stakeholders? A general definition of stakeholders is any person or people who can or are affected by an organisation's actions, decisions, policies, practices or goals (Freeman,1984). With particular reference to evaluation, Green (2005:397) asserts that stakeholders are, "people who have a stake or a vested interest in the programme, policy or product being evaluated...and therefore also have a stake in the evaluation". As such, stakeholder involvement entails practices by an organisation to actively and positively involve the stakeholders in the organisational activities and processes (Greenwood, 2007). People should be involved if they have information that cannot be gained through other ways, or if their participation is necessary to assure successful implementation of the evaluation process.

Research indicates that evaluation systems are more likely to be accepted, successfully implemented, and sustained if stakeholders are included in the design process (Clifford, Hansen \& Wraight, 2012). The stakeholders certify the relevance and validity of a system, therefore, their involvement during the design process ensures that the system is validated from the onset, thereby increasing chances of acceptance (Danielson \& McGreal, 200o). In support of this, Stronge and Tucker (1999) also explain that a participatory approach facilitates political processes of expression and debate while also giving room for concessions which enhances acceptance of the final product. Besides building buy-in, stakeholder involvement can significantly improve the quality of the product created through incorporation of diverse ideas and knowledge (Clifford, Hansen \& Wraight, 2012). The acceptance of the evaluation system in turn aids its sustainability and contributes to its capacity to improve performance (Heneman et al., 2006). To further justify an inclusive approach to the design process, Johnson (1997) explains that the different stakeholders have different interests and perspectives and their representations allows for the concerns of all constituencies to be 
accommodated. The representation of all stakeholders helps in the creation of a product that is acceptable by all constituencies thereby minimising resistance and promoting respect for the process by all. It increases the likelihood of the system being perceived as responsive to the needs of the institution. This, however, requires reasonable amount of negotiations and compromises by the different stakeholders.

One case of success is the Chilean teacher performance evaluation system. This system resulted from the participatory and collaborative efforts of all the key stakeholders. Although the development process was long and took about 10 years to reach consensus, it was worth the while as the active involvement and participation of the key stakeholders, especially the teachers and their unions, promoted buy-in, respect and minimised resistance (Santiago \& Benavides, 2009). The inclusive and participatory nature of the Chilean teacher performance evaluation system has been hailed as one of the system's key strengths.

\subsection{Who are the key stakeholders?}

The performance evaluation of teachers is of interest not only to the teachers themselves but to different stakeholders that include governments, local authorities, school administrators, researchers and teachers' unions or teachers themselves (Isoré,2009). Parents and students also have an interest in the evaluation of teachers. It should however be noted that it may not be feasible nor appropriate to engage all the stakeholders at the same time. It may be prudent to engage different stakeholders for different purposes and at different phases of evaluation planning process. The inclusion of the different stakeholders minimises resistance but on the other hand, increases acceptance and support.

The government of a state is mandated to set the national learning outcome objectives which should be the basis of any performance evaluation process (Isoré, 2009). The government is also responsible for the direct implementation and monitoring of the evaluation process especially in countries where teachers are regarded as civil servants. While setting the agenda, it is critical that the government is represented in the design process of a performance evaluation system. In countries like Zimbabwe, where local authorities also have some schools under their responsibility, it is important that they partake in this important process since they are obligated to ensure quality education provision in the schools under their authority.

The inclusion of educational researchers and teachers is important as they are the experts and know better what good teaching entails and they are also better placed to know how good teaching can be captured (Goe et al., 2014; Isoré,2009). Furthermore, the inclusion of teachers promotes ownership of the system (Stronge \& Tucker, 1999) while on the other hand, their exclusion from the design process promotes division and discord with the administrators which is retrogressive (McLaughlin, 1990). Since the teachers' unions represent the interests of the teachers, their representation in the design process of an evaluation system enhances the acceptance of the product by the constituency that they represent. Given this background, this study thus sought to establish the extent of stakeholder involvement in the design process of the teacher performance evaluation system used in one education district of Zimbabwe.

\subsection{Background information on Zimbabwe}

Since Zimbabwe's independence in 1980, various initiatives have been undertaken that were aimed at improving service delivery of the public employees (Zvavahera, 2014). A number of systems which include the Public finance management system, Mission statements, Clients charter and the Performance appraisal system were tried before the current performance evaluation system (Matunhu \& Matunhu, 2014; Zvavahera, 2014). At independence, the new government of Zimbabwe embarked on an ambitious expansion of the education system at all levels (Chivore, 1992). The programme, however, compromised issues that included staffing, resources and effectiveness of the system in general culminating in an in-depth study and audit of the civil service by the Public Service Commission (PSC) 
in 1987 (Zigora \& Zigwamba, 200o). The study by the PSC was aimed at establishing strategies to improve the quality of service delivery and responsiveness to the needs of the public. This study led to the adoption of Performance Management System (PMS) in 1995 which was targeted at enhancing the effectiveness of the education system and making educators more accountable (Machingambi, 2013). The PMS was aimed at improving the quality of public education and enhancing staff satisfaction and development (Zvobgo, 1998 in Machingambi, 2013).

In 2005, Zimbabwe abandoned PMS in favour of the Results Based Management (RBM) system as a performance evaluation system for the whole public sector including the teachers (Madhekeni, 2012). Different reasons have been given for the abandonment of PMS. One reason given was that the PMS had failed to yield the desired results of quality service delivery (Zvavahera, 2014), and the other reason was that the adoption of RBM was a result of the growing internal and external pressures for government to provide more tangible and demonstrable results (Madhekeni, 2012). A question that comes to mind, whether RBM has yielded the expected results? This study thus sought to establish the influence of the design process on effectiveness of RBM?

Although a number of studies have been conducted on RBM, most of these have focused on the implementation challenges of the system across the different ministries. Not much work has been done to establish the influence of stakeholder involvement on the effectiveness of the RBM, therefore, this study sought to establish the relationship between the design process and the effectiveness of the system. A study by Gutuza (2016) established that one of the impediments to RBM implementation was the lack of involvement of the teachers in the policy formulation process. The exclusion of teachers at this critical stage also limited the clear articulation of the system to these important stakeholders in the evaluation process thereby hindering acceptance and buy-in. Furthermore, Musingafi, Dumbu and Chadamoyo (2013) assert that the imposition of a policy disregarding the presenting environment is an assured way to failure. The teachers as the implementers of the policy in this case therefore had an important contribution in creating the requisite environment for the support and successful implementation of RBM. This suggests that the inclusion of teachers in the design process would assist in enhancing buy-in while on the other hand minimising resistance. Although it has been noted that stakeholder exclusion led to limited buy-in, there remains a gap on establishing the extent to which the exclusion of stakeholders affected the effectiveness of RBM as a teacher performance evaluation system. This study thus helps to address this gap by seeking to determine the relationship between the design process and the effectiveness of a performance evaluation system.

\subsection{The Conceptual Framework}

Svinicki (2010) posits that individuals have assumptions of how reality works and this allows them to envisage how $\mathrm{X}$ is related to $\mathrm{Y}$. These assumptions on the cause-effect relationship on a given phenomenon constitute a conceptual framework. In line with these assertions, we developed a conceptual framework for this study which was informed by literature, and our own experiences. This framework was the lens through which we conducted the study as it guided us in both the data collection and analysis processes. We developed the Readiness Assessment, Design, Process, Significance (RADPS) conceptual framework. The RADPS conceptual framework assumes that readiness assessment, design process, process of implementation and the significance of an evaluation process are key factors that contribute to the efficacy of a performance evaluation system (Musodza, 2019). The works that informed the development of the RADPS conceptual framework include Kusek and Rist (2004), Santiago and Benavides (2009), Shinkfield and Stufflebeam (1995), Stronge (1995) and The New Teacher Project (TNTP) (2010).

This paper confines itself to the Design component of the framework as dictated by its scope. This component of the framework assumes that stakeholder participation and involvement in the design process of an evaluation system is key and contributes to the effectiveness of the system. The active participation of the stakeholders enhances acceptance and buy-in (Heneman et al., 2006; Mayne, 2007), relevance of the system (Isoré, 2009) and support for the system during implementation 
(Riodan, Lacirano-Paquet, Shakman, Bocala \& Chang, 2015).

\section{Aim}

The aim of the study was to establish the impact of stakeholder involvement in the design process of the teacher performance evaluation system of one education district in Zimbabwe.

\subsection{Objectives}

- To establish the educators' opinions on the design process of RBM in one education district of Zimbabwe.

- To determine the extent of the relationship between the design process and effectiveness of RBM.

\section{Research Methodology}

This study was conducted in the Midlands province of Zimbabwe and focused on Kwekwe district. The study was underpinned by the pragmatic worldview which considers and accepts both the objective and subjective knowledge views (Morgan, 2014; Johnson, Onwuegbuzie \& Turner, 2007; Onwuegbuzie \& Leech, 2007). Pragmatism emphasises on what works to solve a problem and is not stuck to a particular methodological approach thereby opening it up to the use of both the quantitative and qualitative approaches (Creswell, 2013; Feilzer, 2010). The pragmatic paradigm allows for the exploitation of the strengths of the different approaches while at the same time providing an opportunity to cancel out the 'methodical effect' of the quantitative and qualitative approaches. (Morgan, 2014). Informed by the pragmatic paradigm, the study, thus, adopted the mixed method design to allow for a comprehensive and deep examination of the influence of stakeholder involvement on the effectiveness of RBM. The convergent mixed method design that involves the collection and analysis of quantitative data separately but concurrently was employed (Creswell, 2014; Teddlie \& Tashakkori, 2009). The convergent design allowed us to corroborate findings from the two data sets and provided a more comprehensive understanding of the phenomenon under study as the patterns and trends from the survey were explained by the narratives from the interviews.

\subsection{Sampling and sample}

The study population was 985 educators in 55 secondary schools of Kwekwe district. To select the participants for the study, we used the concurrent parallel sampling design. The quota sampling technique was used to select 5 rural and 5 urban public secondary schools for the survey. The convenient sampling technique based on easy of access was used to select two rural and two urban schools from the ten schools to participate in the interviews. Schools that were defined as rural were located at least $45 \mathrm{~km}$ from the town centre and under the jurisdiction of a rural district council. The participants for the two strands of the study were selected simultaneously from the same underlying population but had a parallel relationship since the samples were different (Collins, Onwuegbuzie \& Jiao, 2007). The inclusion criteria were that the participants should have been in service by the time the Ministry of Education adopted RBM as a teacher performance evaluation system.

\subsubsection{Quantitative sample}

The quantitative sample was selected using simple random sampling which is a probabilistic sampling technique. Probability sampling is premised on principles of randomness and probability which permits for the accurate generalisation of findings to the population (Maree \& Pietersen, 2016). The 
simple random sampling technique allowed each member of the population an equal chance of inclusion in the sample (Crano \& Brewer, 2002; Creswell, 2014; Onwuegbuzie \& Collins, 2007; Teddlie $\& \mathrm{Yu}, 2007)$. We decided on a confidence level of $95 \%$ and an error margin of $5 \%$. Since the population parameter was known, we then used a sample size determination table to determine the sample size (Crano \& Brewer, 2002). We rounded our population from 985 to 1000 which translated to a sample size of 278 according to the sample determination table (Cohen, Manion \& Morrison, 2011; Krejcie \& Morgan, 1970). To cater for the non-response rate, 310 participants were selected and a total of 292 questionnaires were returned which was an adequate and representative figure for the population.

\subsubsection{Qualitative sample}

The quota sampling technique was used to select the qualitative sample. Three strata were identified in the population and these were the classroom teachers, Heads of Departments (HoDs) and school heads. To get cases with high information power, participants that were selected had been in service by the time RBM was adopted as a teacher performance evaluation system, and, to determine the sample size, we were guided by the principles of information power and data saturation. We thus settled for a sample size of 12 composed of 4 people from each of the stratum.

\subsection{Validity and reliability}

Measures were observed to ensure the reliability and validity of the questionnaire. The internal reliability and test-retest reliability of the questionnaire were checked. The Cronbach's alpha coefficient value was 0.95 indicating that the items in the questionnaire were sufficiently correlated (Scholtes, Terwee \& Poolman, 2011). The co-efficient of stability value from the test-retest reliability was 0.90 proving high reliability of the instrument (Pietersen \& Maree, 2016). To further enhance the quality of the questionnaire, the face and content validity of the questionnaire were checked by peers and experts before and during piloting.

The interview schedule was pilot-tested to assess the relevance and clarity of the questions, flow of the questions and determine the average time required for an interview. The additional measures that were taken to ensure the trustworthiness of the data included triangulation of sources, member checking and debriefing sessions (Cohen et al., 2011; Teddlie \& Tashakkori, 2009).

\subsection{Data analysis}

Data from the completed questionnaires was analysed using the Statistical Package for Social Sciences (SPSS) version 26. Descriptive and inferential statistical analyses were conducted. Qualitative data were analysed using ATLAS ti. 8.

\section{Results}

The results for the two objectives were as follows:

\subsection{Objective 1: The educators' opinions on the design process of RBM}

A summary of the teachers' views on stakeholder involvement is presented in table 1. 
Table 1: Perceptions of teachers on the design process

\begin{tabular}{|c|c|c|c|c|c|}
\hline & \multicolumn{5}{|c|}{ Frequency /Percentage } \\
\hline Design process of teacher performance evaluation system & S D & D & NS & A & S A \\
\hline $\begin{array}{l}\text { There was adequate consultation when the teacher performance } \\
\text { evaluation system was designed. }\end{array}$ & $\begin{array}{c}95 \\
32.5 \%\end{array}$ & $\begin{array}{c}80 \\
27 \cdot 4 \%\end{array}$ & $\begin{array}{c}69 \\
23.6\end{array}$ & $\begin{array}{c}44 \\
15.1 \%\end{array}$ & $\begin{array}{c}4 \\
1.4 \%\end{array}$ \\
\hline I know enough about what constitute good teaching as a practitioner. & $\begin{array}{c}16 \\
5 \cdot 5 \%\end{array}$ & $3.8 \%$ & $\begin{array}{c}28 \\
8.9 \%\end{array}$ & $\begin{array}{c}151 \\
51.7 \%\end{array}$ & $\begin{array}{c}86 \\
29.6 \%\end{array}$ \\
\hline $\begin{array}{l}\text { I know the methods that can be used to get accurate performance } \\
\text { information. }\end{array}$ & $\begin{array}{c}18 \\
6.2 \%\end{array}$ & $\begin{array}{c}38 \\
13 \%\end{array}$ & $\begin{array}{c}74 \\
25 \cdot 3 \%\end{array}$ & $\begin{array}{c}126 \\
43.2 \%\end{array}$ & $\begin{array}{c}36 \\
12.3 \%\end{array}$ \\
\hline $\begin{array}{l}\text { My opinion is that the design of the teacher evaluation system has } \\
\text { impacted positively on teacher performance evaluation effectiveness. }\end{array}$ & $\begin{array}{c}60 \\
20.5 \%\end{array}$ & $\begin{array}{c}105 \\
36 \%\end{array}$ & $\begin{array}{c}61 \\
20.9 \%\end{array}$ & $\begin{array}{c}19 \\
6.5 \%\end{array}$ & $\begin{array}{c}47 \\
16.1 \%\end{array}$ \\
\hline
\end{tabular}

In seeking to establish the perceptions of the teachers on the design process of the evaluation system, interesting perspectives emerged on stakeholder involvement. Table 1 presents a summary of the teachers views from the survey. As illustrated in Table 1, most of the respondents, 175 (59.9\%) pointed out that the design process had been non participatory as they had been excluded. The opinion of these teachers was corroborated by many of the interview participants who echoed that there had been no stakeholder involvement in the design process of RBM but that the system was simply imposed. To illustrate this point, one participant stated that, "We were never involved in anything... We were simply told that there is a new system and we should adhere to the new system. We were never involved as stakeholders". This statement substantiates the position of most of the teachers in the survey about the exclusion of the teachers in the design process of RBM. It was explained that the system was simply imposed without any discussion with the teachers. To support the claim, another participant added that, "As far as I know, we were not involved in the design process. Like I said, we had the KRA system before RBM and out of the blue, we were told that we are now using RBM system, so we were not involved in any way" (HOD 3 ). Sentiments from the interviews also implied that besides being excluded from the design process, the teachers were not even aware of who had or how RBM was developed. This was proved by some statements like, "It was just imposed on us... How it was developed, I am not aware" (School head 1). Another participant added that, "I don't know (laughs) I simply have to use that instrument but I don't know how it was developed" (HOD 1). These statements highlighted that the design and development of RBM was a non-participatory exercise which left out some key stakeholders like the teachers.

Although literature asserts that teachers as experts in their own field should be represented in the design of a teacher performance evaluation system, the evidence from the majority of the teachers, $237(81.2 \%)$ was that in spite of being knowledgeable about what constitutes good teaching, they were however not engaged in the design process of the teacher evaluation system in use. The majority of teachers, $162(55.5 \%)$, also indicated that there were conversant with the methods that can be used to capture correct and truthful teacher performance information although they had been left out of the design of the teacher performance evaluation system in use. This was also confirmed during the interviews through statements such as, "We are the experts and the logical thing was for us to be involved in the design process, but surprisingly, we were side-lined" (Teacher 1). Another interviewee explained, "There is a saying that, to catch thief, send a thief. We were however left out although we know the best strategies that can be used to capture real teacher performance" (HOD 3). The general view of the educators was that they should have been involved in the design process as experts in their field. These views imply that teacher involvement would have enhanced the appropriateness of the evaluation system. The conclusion by most of the teachers, $165(56.5 \%)$, was that, the design process had a negative impact on the effectiveness of RBM as a teacher performance evaluation system. 
4.2 Objective 2: The relationship between the design process and effectiveness of RBM

Table 2: Model Summary

\begin{tabular}{|c|c|c|c|c|}
\hline \multicolumn{5}{|c|}{ Model Summary } \\
\hline Model & $\mathrm{R}$ & R Square & Adjusted R Square & Std. Error of the Estimate \\
\hline 1 & $.999^{\mathrm{a}}$ & .998 & .998 & .02708 \\
\hline \multicolumn{5}{|c|}{ a. Predictors: (Constant) A, Design, C, D } \\
\hline
\end{tabular}

Table 2 shows the model summary which determines how well the regression model fits the data. The model summary presents the $\mathrm{R}$ and $\mathrm{R}^{2}$ results where the $\mathrm{R}$ value represents the simple correlation and the $\mathrm{R}^{2}$ indicates how much of the total variation in the dependent variable (effectiveness) is explained by the independent variables. The $\mathrm{R}$ value (o.99) indicate a high degree of correlation between the dependent variables and the predictors. In this case, the R square value was 0.998 , meaning that $99.8 \%$ of the variation in time was explained by the model. An R square value of $>0.5$ or $50 \%$ means strong fit (Muijs, 2004). The R square value of $99.8 \%$ therefore meant that the regression model was a strong fit for the data.

\subsubsection{Statistical significance of the model}

The ANOVA tests shows acceptability of the model from a statistical perspective and reports how well the regression equation fits the data. The ANOVA results for this study are presented in Table 3 .

Table 3: ANOVA

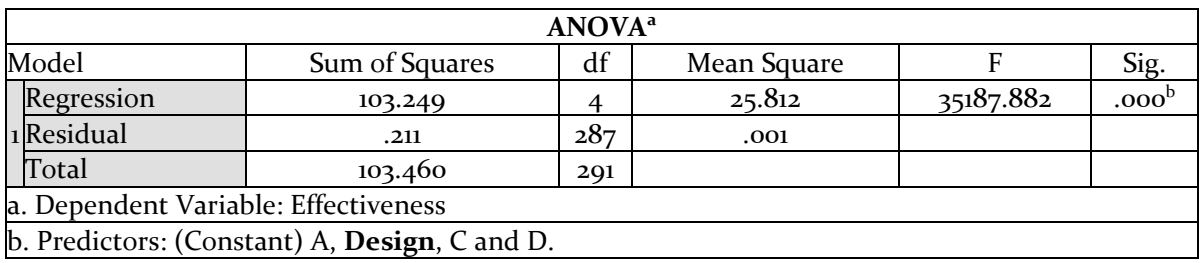

Table 3 shows the ANOVA which reports how well the regression equation fits the data. The significant value of o.ooo proved that there is a statistically significant relationship between the independent variables and the dependent variable (Cohen et al., 2011). In other words, the independent variables including design process are statistically significant in predicting the effectiveness of teacher performance evaluation system, meaning that, the variation explained by the model is not due to chance.

\subsubsection{Estimated model coefficients}

The Beta coefficient value explains the strength of the relationship between the independent variable and the dependent variable. It explains the extent of the influence of the design process on the effectiveness of the teacher performance evaluation system. The results of the coefficient tests are presented in Table 4. 
Table 4: Coefficients

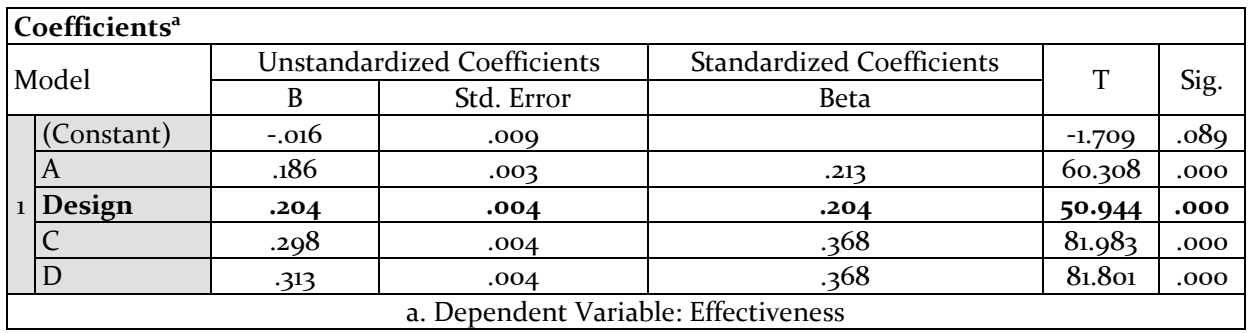

Beta coefficient is the degree of change in the outcome of the dependent variable for every one unit of change in the predictor or independent variable. We used the standardised Beta coefficient which had a value of 0.204 for the design process. The results mean that for every one unit of change in the design process, then, the outcome variable of effectiveness increased by 0.204 units. This proves the influence of the design process on the effectiveness of an evaluation system. These findings were corroborated by a participant in the interviews who indicated that, "I think it takes a teacher to design an appropriate and relevant system that can capture effective teaching. Involving people who are not the users leads to faulty systems that are ineffective" (Teacher 3). This was further supported by another participant who pointed out that, "The system needs to be improved and the implementers should be involved so that the evaluation system can be made to capture effective teaching otherwise the exercise becomes a futile one" (HOD 4). These sentiments from the participants emphasised the importance of stakeholder involvement to guarantee the effectiveness of the performance evaluation system.

\section{Discussion of Results}

The exclusion of teachers during the design process has led to the rejection and disapproval of RBM by most educators. Evidence suggests that most teachers have failed to embrace the system even though it has been in use as a performance evaluation system for many years now. To illustrate the rejection, one participant said, "There is need to involve the teachers because we have not accepted it as it is something that was just imposed on us in a draconian way. We are simply doing it for compliance otherwise we don't see its benefits" (Teacher 1). This was further supported by another participant who said, "I think it should be stopped forthwith. I do not think that it is necessary at all in the schools. It wasn't in the schools when I joined service and we have always been working hard because we have set targets in the form of the departmental policies" ( $\mathrm{HOD}_{3}$ ). The rejection has been attributed to lack of stakeholder involvement during the design process and this was also noted by Machingambi (2013) and Gutuza (2016). Machingambi (2013) attributed the lack of enthusiasm for the performance evaluation process by the teachers to their exclusion during the planning and design phases of the system. Musingafi et al., (2013) also reiterated this position by explaining that the imposition of a programme on the people is a guarantee for failure and a recipe for disaster. The findings of the study also validated the propositions of the RADPS conceptual framework for a collaborative and inclusive approach of the key stakeholders in the development of an evaluation system. This study thus proved that stakeholder involvement in the design of a performance evaluation system is critical in minimising resistance and promoting buy-in as supported by other studies (Heneman et al. in Isoré, 2009; Mayne, 2007).

Research further argues that for a system to be embraced and respected, it should have been borne out of the concerted effort of all key stakeholders (Goe et al, 2014; Stronge \& Tucker, 1999; White et al., 2012). This is also supported by Danielson and McGreal's (2000) assertion that, it is only the users of a system that certify its relevance and validity, thereby making it prudent to involve them from the onset. The involvement of stakeholders promotes ownership of the system by the key users which was however lacking in this case. Creating a platform that allows the expression and discussion of ideas 
leading to negotiations before policy adoption and implementation enhances the quality of the final product and its acceptance by the key constituencies. This also ensures the marketability of the final product to new entrants into the education system.

The results of the multiple regression analysis indicated that there is a statistically significant relationship between the design process and effectiveness of an evaluation system. The beta coefficient results proved that for each unit increase in design, then, the effectiveness of an evaluation system increases by 0.204 units. This confirmed the importance of the design process in relation to the effectiveness of an evaluation system in line with the assumptions of the RADPS conceptual framework. The RADPS conceptual framework assumes that the design process influences the effectiveness of a performance evaluation system (Musodza, 2019).

\section{Conclusion}

The findings from this study that the design process was exclusive and non-participatory form the basis for us to concluded that the design process of RBM was faulty. Educators highlighted that neither they nor their unions were involved in the designing of RBM. They indicated that they were left out of the design process in-spite of their knowledge and expertise of what constitutes effective teaching and how it can be measured. Their exclusion as experts in the field led the teachers to lose confidence in the system and its ability to capture teacher performance accurately. The study also concluded that RBM was not pilot tested to give the teachers an opportunity to give their input and contributions to enhance the relevance and credibility of the evaluation system. Whatever good attributes that RBM possesses has thus been overshadowed by the non-participatory nature of its design process. The educators have failed to accept the performance evaluation system years after its introduction. The educators still referred to RBM as 'their thing', signalling lack of ownership. This study therefore concluded that the non-participatory and top-down design process negatively impacted the effectiveness of RBM in the district.

\section{Implications of the Study}

The findings of the study have a number of implications. The findings reveal the importance of the design process relative to the effectiveness of the evaluation process and system. The significance of a consultative, participatory and inclusive design process is also highlighted. The findings therefore suggest the need for policy makers to revisit the policy formulation approach with a view of making it consultative and participatory so as to promote ownership, respect and buy-in. It should be noted that even if teachers had been excluded from the initial planning and design processes, piloting widely the performance evaluation system before full scale adoption and implementation would have provided an opportunity for the teachers to give their input on the relevance of the system thereby increasing its chances of being accepted. In view of this, this study therefore recommends that policy formulation should include all the key stakeholders and that any new programme should be pilot tested before full scale implementation to give room for feedback from the users.

\section{References}

Chivore, B. R. S. (1992). Pre-service teacher education at a distance: The case of Zimbabwe. Distance education in Anglophone Africa, 103-115.

Clifford, M., Hansen, U. J., \& Wraight, S. (2012). A Practical Guide to Designing Comprehensive Principal Evaluation Systems: A Tool to Assist in the Development of Principal Evaluation Systems. National Comprehensive Center for Teacher Quality.

Cohen, L., Manion, L., and Morrison, K. (2011). Research methods in education. $7^{\text {th }}$ Ed. London: Routledge.

Collins, K. M., Onwuegbuzie, A. J., \& Jiao, Q. G. (2007). A mixed methods investigation of mixed methods sampling designs in social and health science research. Journal of mixed methods research, 1(3), 267-294. 
Crano, W. D., \& Brewer, M. B. (2002). Principles and methods of social research. $2^{\text {nd }}$ ed. New Jersey:Lawrence Erlbaum Associates Publishers, Inc.

Creswell, J.W. (2013). Qualitative inquiry and research design: Choosing among five approaches. $3^{\text {rd }}$ ed. Thousand Oaks: Sage Publications, Inc.

Creswell, J.W. (2014). Research design: Qualitative, quantitative, and mixed methods approaches. Thousand Oaks: Sage Publications, Inc.

Danielson, C., \& McGreal, T. L. (200o). Teacher evaluation to enhance professional practice. Ascd.

Feilzer, Y. M. (2010). Doing mixed methods research pragmatically: Implications for the rediscovery of pragmatism as a research paradigm. Journal of mixed methods research, 4(1), 6-16.

Freeman, R. E. (1984). Strategic management: A stakeholder approach. Boston: Pitman.

Goe, L., Holdheide, L., \& Miller, T. (2014). A Practical Guide to Designing Comprehensive Teacher Evaluation Systems: A Tool to Assist in the Development of Teacher Evaluation Systems. National Comprehensive Center for Teacher Quality. Retrieved from: https://files.eric.ed.gov Accessed on 27/11/16

Greenwood, M. (2007). Stakeholder engagement: Beyond the myth of corporate responsibility. Journal of Business ethics, $74(4)$, 315-327.

Guerci, M., \& Shani, A. B. R. (2014). Stakeholder involvement in human resource management practices: Evidence from Italy. management revue, 80-102.

Guest, G., Bunce, A., \& Johnson, L. (2006). How many interviews are enough? An experiment with data saturation and variability. Field methods, $18(1), 59-82$.

Gutuza, R. F. (2016). An investigation on the challenges faced by schools in implementation of the result based management system in Mutasa district of Zimbabwe. Global Journal of Advanced Research, 3(5), 389-396.

Hassan, K. (2016). Re: In regression, what are the beta values and correlation coefficients used for and how are they interpreted? Retrieved from: https://www.researchgate.net/post/In_regression_what_are_the_beta_values _and_correlation_coefficients_used_for_and_how_are_they_interpreted/5747f3od93553b4569465411/citatio n/download.

Heneman III, H. G., Milanowski, A., Kimball, S., \& Odden, A. (2006). Standards-based teacher evaluation as a foundation for knowledge-and skill-based pay. CPRE Policy Briefs. Retrieved from http://repository.upenn.edu/cpre_policybriefs/33 Accessed on 5/10/18.

Isoré, M. (2009). "Teacher Evaluation: Current Practices in OECD Countries and a Literature Review", OECD Education Working Papers, No. 23, Paris: OECD Publishing. Available from: http://dx.doi.org/10.1787/223283631428 Accessed on 4/10/17.

Johnson, B. L. (1997). An organizational analysis of multiple perspectives of effective teaching: Implications for teacher evaluation. Journal of Personnel Evaluation in Education, 11(1), 69-87.

Johnson, R. B., Onwuegbuzie, A. J., \& Turner, L. A. (2007). Toward a definition of mixed methods research. Journal of mixed methods research, $1(2), 112-133$.

Krejcie, R. V., \& Morgan, D. W. (1970). Determining sample size for research activities. Educational and psychological measurement, 30(3), 607-610.

Kusek, J. Z, \& Rist, R. C. (2004). Ten steps to a results-based monitoring and evaluation system: a handbook for development practitioners. The World Bank. Retrieved from: https://openknowledge.worldbank.org /bitstream/handle/10986/14926/296720PAPERo10osteps.pdf Accessed on 19/12/17

Machingambi, S. (2013). Teachers' Perceptions on the Implementation of the Performance Management System in Zimbabwe. International Journal of Educational Sciences, 5(3), 217-225.

Madhekeni, A. (2012). Implementing results-based management systems in Zimbabwe: Context and implications for the public sector. International Journal of Humanities and Social Science, 2(8), 122-129.

Maree, K. \& Pietersen, J. (2016). Sampling. In Maree, K. (Ed) First steps in research 2. $2^{\text {nd }}$ Edition. Pretoria: Van Schaik Publishers.

Matunhu, J., \& Matunhu, V. (2014). A review of the implementation of public service reforms by Zimbabwe Revenue Authority (2011). Journal of Social Sciences, 38(1), 63-70.

Mayne, J. (2007). Challenges and lessons in implementing results-based management. Evaluation, 13(1), 87-109.

McLaughlin, M.W. (1990). Embracing contraries: Implementing and sustaining teacher evaluation. In J. Millman, and L. Darling-Hammond (Eds.), The new handbook of teacher evaluation: Assessing elementary and secondary school teachers. Newbury Park, CA: Sage Publications.

Morgan, D.L. (2014). Integrating qualitative and quantitative methods: A pragmatic approach. Thousand Oaks: Sage Publications, Inc.

Muijs, D. (2004). Doing Quantitative Research in Education with SPSS. London:Sage.

Musingafi, M. C., Dumbu, E., Chadamoyo, P., \& Campus, M. R. (2013). Improving Performance in the African Civil Service: Empirical Evidence from Zimbabwe. Public Policy and Administration Research, 3(2), 19-26. 
Musodza, B.R. (2019). Effectiveness of the teacher performance evaluation system of Kwekwe district in Zimbabwe (Unpublished doctoral thesis). University of Venda, South Africa.

Onwuegbuzie, A. J., \& Collins, K. M. (2007). A typology of mixed methods sampling designs in social science research. Qualitative Report, 12(2), 281-316.

Pietersen, J. and Maree, K. (2016). Standardisation of a questionnaire. In Maree, K. (Ed) First steps in research $2.2^{\text {nd }}$ Edition. Pretoria: Van Schaik Publishers.

Riordan, J., Lacireno-Paquet, N., Shakman, K., Bocala, C., \& Chang, Q. (2015). Redesigning teacher evaluation: Lessons from a pilot implementation. Washington, DC: International Center for Education Evaluation and Regional Assistance and North East Educator Effectiveness Research Alliance.

Santiago, P., \& Benavides, F. (2009). Teacher Evaluation: A Conceptual Framework and Examples of Country Practices, paper presented at the OECD-Mexico Workshop "Towards a Teacher Evaluation Framework in Mexico: International Practices, Criteria and Mechanisms”, Mexico City, 1-2 December 20o9. Retrieved from: http://www.oecd.org/edu/school/44568106.pdf Accessed on 17/o9/17

Scholtes, V. A., Terwee, C. B., \& Poolman, R. W. (2011). What makes a measurement instrument valid and reliable?. Injury, 42(3), 236-240.

Shinkfield, A. J., \& Stufflebeam, D. L. (1995). Teacher evaluation: Guide to effective practice (Vol. 41). Teacher Evaluation: Guide to Effective Practice. Boston: Kluwer Academic Publishers. Retrieved from: http://files.eric.ed.gov/fulltext/ED435632.pdf Accessed on 17/o9/17.

Stronge, J. H., \& Tucker, P. D. (1999). The politics of teacher evaluation: A case study of new system design and implementation. Journal of Personnel Evaluation in Education, 13(4), 339-359.

Stronge, J. H. (1995). Balancing individual and institutional goals in educational personnel evaluation: A conceptual framework. Studies in Educational Evaluation, 21(2), 131-151.

Svinicki, M. D. (2010). A guidebook on conceptual frameworks for research in engineering education. Rigorous Research in Engineering Education, 7(13), 1-53.

Teddlie, C., \& Tashakkori, A. (2009). Foundations of Mixed Methods Research: Integrating Quantitative and Qualitative Approaches in the Social and Behavioral Sciences. Thousand Oaks: SAGE Publications.

Teddlie, C., \& Yu, F. (2007). Mixed methods sampling: A typology with examples. Journal of mixed methods research, $1(1), 77-100$.

The New Teacher Project. (2010). Evaluation 2.0 [Online] Available from: www.tntp.org/assets/documents/Teacher-Evaluation-Oct1oF.pdf Accessed on 18/10/15.

Verma, Ajay. (2020). Re: In regression, what are the beta values and correlation coefficients used for and how are they interpreted?. Retrieved from: https://www.researchgate.net/post/In_regression_what_are_the_beta _values_and_correlation_coefficients_used_for_and_how_are_they_interpreted/5e5caod7fofb62158coa486f/ citation/download

White, B. R., Cowhy, J., Stevens, W. D., \& Sporte, S. E. (2012). Designing and Implementing the Next Generation of Teacher Evaluation Systems: Lessons Learned from Case Studies in Five Illinois Districts. Research Brief. Consortium on Chicago School Research. 1313 East 6oth Street, Chicago, IL 60637.

Zigora, P., \& Chigwamba, S. (200o). Management of human resources in Africa: Challenges for the third millennium, paper presented at the Public Service Workshop "Performance Management in the Public Service", Harare, 14-17 August 1999.

Zvavahera, P. (2014). An evaluation of the effectiveness of performance management systems on service delivery in the Zimbabwean civil service. Journal of Management and Marketing Research, 14, 1. 